\title{
Nest boxes do not cause a shift in bat community composition in an urbanised landscape
}

\author{
Stephen R. Griffiths $\mathbb{1}^{1 *}$, Linda F. Lumsden ${ }^{2}$, Kylie A. Robert $\mathbb{D}^{1}$ \& Pia E. Lentini $\mathbb{\oplus}^{3}$ \\ Nest boxes are often used to provide supplementary roosts for cavity-dependent wildlife, but little \\ is known about if they influence faunal community composition. Long-term monitoring of bat \\ boxes in south-eastern Australia indicated that their use was dominated by one generalist species \\ (Chalinolobus gouldii), causing concern that installing bat boxes could cause a shift toward less diverse \\ bat communities. To test this, we conducted a large-scale before-after control-impact experiment at 18 \\ sites, over five years. Sites were either: (1) those with existing bat boxes, (2) those where boxes were \\ added during the study, or (3) controls without boxes. We used echolocation call data from 9035 bat \\ detector nights to compare community composition, diversity, and species' relative activity between \\ the sites. Chalinolobus gouldii continued to dominate the use of existing boxes, but we found little \\ difference in community composition between sites based on the presence, absence, or addition of \\ boxes. Our study is the first to explore the influence installing artificial hollows has on localized faunal \\ assemblages over spatio-temporal scales relevant to management. We conclude that there is cause for \\ optimism that bat boxes might not have perverse outcomes on local community composition in the \\ short- to medium-term, as we had feared.
}

Tree hollows and cavities are keystone habitats used by a broad range of fauna for shelter and breeding ${ }^{1}$. The clearing of large, old trees during timber harvesting, urban developments, and for risk mitigation therefore presents a major ongoing threat for cavity-dependent wildlife ${ }^{2}$. Consequently, artificial cavities (nest or roost boxes) are often used to provide supplementary microhabitats for wildlife in human-disturbed landscapes where natural tree cavities have been depleted ${ }^{3}$. The installation of nest boxes has led to positive conservation outcomes for some species, such as the common hoopoe (Upupa epops) ${ }^{4}$, Gouldian finch (Erythrura gouldiae) ${ }^{5}$, and Leadbeater's possum (Gymnobelideus leadbeateri) ${ }^{6}$. In these species-specific programs, boxes are designed in a targeted manner to attract the species of interest, whilst also attempting to exclude non-target taxa ${ }^{7}$. These programs also often adopt on-going systematic monitoring to empirically assess the effectiveness of a range of factors relating to the design and installation of the boxes, to increase their suitability for the target species 6,8 .

While a range of different box sizes, shapes and construction materials have been trialled for tree-cavity roosting insectivorous bats (hereafter 'bats'), bat box designs are typically not species-specific'. They can be constructed from a range of materials, including timber ${ }^{10}$, plywood $^{11}$, polyester resin ${ }^{12}$, and woodcrete ${ }^{13}$, and can be used by any species small enough to pass through the open slit entrance at the bottom of the box ${ }^{10,11}$. In spite of this, the majority of studies show that bat boxes are typically used by 1-3 mostly widespread and common spe$\mathrm{cies}^{9}$, regardless of the local bat community assemblage. This is a concern for bat box programs in urbanised areas, where boxes are frequently deployed by land managers (e.g. local councils) and community groups targeting the whole bat community, not just individual species ${ }^{14-16}$.

Bats are often a relatively diverse and abundant component of the native mammalian fauna in urbanised landscapes ${ }^{17,18}$, but these communities are typically dominated by disturbance-adapted, generalist species ${ }^{19,20}$. These species are also more likely to roost in artificial structures than those with more specialised roosting requirements ${ }^{19}$. Hence, there is growing concern that the installation of bat boxes in urbanised areas may boost populations of widespread, disturbance-adapted species, to the detriment of less common, disturbance-sensitive species $^{9,16,21,22}$.

\footnotetext{
${ }^{1}$ Department of Ecology, Environment and Evolution, La Trobe University, Bundoora, 3086, Victoria, Australia. ${ }^{2}$ Arthur Rylah Institute for Environmental Research, Department of Environment, Land, Water and Planning, Heidelberg, 3084, Victoria, Australia. ${ }^{3}$ School of BioSciences, The University of Melbourne, Parkville, 3010, Victoria, Australia. *email: s.griffiths@latrobe.edu.au
} 


\begin{tabular}{|l|l|l|l|l|l|}
\hline Name of park/reserve, suburb & Site code & Site treatment & $\begin{array}{l}\text { No. } \\
\text { boxes }\end{array}$ & $\begin{array}{l}\text { Box check } \\
\text { period }\end{array}$ & $\begin{array}{l}\text { No. box } \\
\text { checks }\end{array}$ \\
\hline Gresswell Nature Conservation Reserve, Macleod & GNCR & Existing boxes & 29 & $2005-2018$ & 64 \\
\hline La Trobe University Wildlife Sanctuary, Bundoora & LTUWS & Existing boxes & 37 & $2009-2018$ & 50 \\
\hline Organ Pipes National Park, Keilor North & OPNP & Existing boxes & 40 & $2012-2018$ & 41 \\
\hline Wilson Reserve, Ivanhoe & WR & Existing boxes & 20 & $2011-2018$ & 78 \\
\hline Shepperds Bush Park, Wantirna South & SB & Box addition & 24 & 2017 & 1 \\
\hline Woodlands Historic Park, Greenvale & WHP & Box addition & 24 & $2017-2018$ & 2 \\
\hline Westerfolds Park, Templestowe & WP & Box addition & 24 & 2017 & 1 \\
\hline Yellow Gum Park, Plenty & YGP & Box addition & 24 & 2017 & 1 \\
\hline Bolin Bolin Billabong, Bulleen & BBB & Control & 0 & n/a & n/a \\
\hline Brimbank Park, Keilor East & BP & Control & 0 & n/a & n/a \\
\hline Currawong Bush Park, Doncaster East & CBP & Control & 0 & n/a & n/a \\
\hline Grange Heathland Reserve, Clayton South & GHR & Control & 0 & n/a & n/a \\
\hline Plenty Gorge Park, South Morang & PGP & Control & 0 & n/a & n/a \\
\hline Tullamarine Airport Greybox Woodland, Melbourne Airport & TA & Control & 0 & n/a & n/a \\
\hline The 100 Acres Reserve, Park Orchards & TOA & Control & 0 & n/a & n/a \\
\hline Valley Reserve, Mount Waverley & VR & Control & 0 & n/a & n/a \\
\hline Yarra Bend Park, Fairfield & YBP & Control & 0 & n/a & n/a \\
\hline Yan Yean Reservoir, Yan Yean & YYR & Control & 0 & n/a & n/a \\
\hline
\end{tabular}

Table 1. Study site treatments and bat-box monitoring survey effort. During a single 'box check', all the boxes at that site were checked on the same day for the presence of bats.

Here, we build on key findings from a long-term bat-box monitoring program in Melbourne, south-eastern Australia. Bat boxes were installed by land managers and conservation-focused community groups at three suburban parks and one peri-urban park between 1994 and 2005, and monitoring has been regularly undertaken since. The aim of the bat box program was to provide supplementary artificial roosts for the community of bats present across Greater Melbourne ${ }^{23,24}$, which includes at least ten Vespertilionidae, three Molossidae, and one Miniopteridae ${ }^{25}$. However, one disturbance-adapted species with a generalist roosting ecology, the Gould's wattled bat (Chalinolobus gouldii), has dominated the use of boxes at all four sites ${ }^{16}$. Annual trapping surveys conducted over more than 30 years at one site have also shown that the use of boxes by C. gouldii has corresponded to a disproportionate increase in its relative abundance in the local area ${ }^{26}$, though the generality of this finding warrants further investigation.

In this study, we conduct a large-scale, before-after control-impact (BACI) experiment to determine whether the addition of bat boxes leads to localised changes in bat community composition. We used ultrasonic bat detectors to document species' relative activity while the bats are in flight at parks and reserves located within the urban matrix across Greater Melbourne, that either had existing bat boxes, had new bat boxes added during the study, or acted as control sites without bat boxes. We hypothesised that installing new bat boxes would cause localised changes in composition, such that communities would become less diverse and be dominated by widespread, disturbance-adapted species ${ }^{16,19,21,26}$. We discuss our findings in the context of empirically assessing the value of bat box programs for conserving entire bat communities in human-disturbed landscapes.

\section{Methods}

Our study sites were 18 parks and reserves widely spread across the Greater Metropolitan area of Melbourne, Victoria, south-eastern Australia $\left(37^{\circ} 48^{\prime} \mathrm{S}, 144^{\circ} 55^{\prime} \mathrm{E}\right.$, Table 1$)$. We employed a BACI study design, and assigned sites to one of three treatment groups: (1) those with existing bat boxes, that had established populations of bats using them ('existing boxes'; $\mathrm{n}=4$ ), (2) those where we added new bat boxes during the study ('box addition'; $\mathrm{n}=4$ ), and ( 3 ) those that acted as control sites without bat boxes ('control'; $\mathrm{n}=10$ ) (Table 1 ).

Bat detector surveys. Bat echolocation calls (henceforth 'passes') were recorded at all 18 sites concurrently using ultrasonic bat detectors (Anabat SD1 and SD2, Titley Scientific, Queensland, Australia). A single detector was placed along a flyway (a walking path or unsealed road) at each site inside a weatherproof box secured to the trunk of a tree at a height of $5 \mathrm{~m}$. Detector microphones were housed within a plastic spout and angled upward at $45^{\circ}$, to prevent rain damage. All detectors were set to Division Ratio 8 and calibrated prior to deployment by adjusting their sensitivity levels against an ultrasound frequency generator ${ }^{27}$. They were programmed to start recording $1 \mathrm{~h}$ before sunset and to stop $30 \mathrm{~min}$ after sunrise, during which time the detectors were triggered automatically by ultrasonic noise.

We conducted 'Before' bat detector surveys at all 18 sites continuously over an 18-month period (4 September 2013 to 23 March 2015, henceforth the 'Before-entire' survey). During this period, the total number of survey nights per site ranged from 190-553; some detectors occasionally turned off when they could not get adequate charge from the solar panel due to cloud cover (Supplementary Material Table S1).

Ninety-six bat boxes constructed from marine plywood were installed across the four 'box addition' sites in April 2015 (Table 1). At each site, 24 boxes were attached to trees at heights ranging from 5-6 m above ground 
level: 16 single-chamber Bat Conservation International design boxes ${ }^{11}$, four cuboid-shaped boxes ${ }^{28}$, and four wedge-shaped boxes ${ }^{29}$ (Supplementary Material Fig. S1). A box check in December 2017 (32 months after installation) revealed that bats were using these new boxes, at which point a follow-up bat detector survey (i.e. post-impact) was conducted concurrently at all 18 sites. Detectors were placed at exactly the same locations at each site during the Before and After survey periods. The 'After-autumn' survey was carried out over 60 consecutive nights from 26 February to 26 April 2018. Because bat activity can vary seasonally according to species ${ }^{30}$, we took a subset of the Before-entire dataset that matched the exact dates of the After-autumn survey, for the sake of comparing community composition just within the autumn months (i.e. 26 February to 26 April 2014 and 26 February to 23 March 2015). This dataset is called the 'Before-autumn' survey herein.

We conducted bat detector surveys over much longer time frames than are typically employed for ecological studies investigating temporal patterns of bat activity. The extended survey length was intended to minimise the influence that variation in weather conditions can have on bat activity, both within and between nights ${ }^{31-34}$, and to maximise the precision of our estimates of different species' relative activity ${ }^{35,36}$.

Call and data analyses. For each study period and at each site we quantified community composition by calculating the relative activity of each species (number of passes per night per species). Bat passes were identified with automated AnaScheme software and a regionally specific identification key ${ }^{37-39}$. Several congeneric species present in the region cannot be reliably distinguished acoustically and so were combined into species complexes: Nyctophilus spp. includes both Gould's long-eared bat (Nyctophilus gouldi) and lesser long-eared bat (Nyctophilus geoffroyi); and Scotorepens spp. includes the inland broad-nosed bat (Scotorepens balstoni) and eastern broad-nosed bat (Scotorepens orion) ${ }^{25}$. One obligate cave-roosting species, the eastern bent-winged bat (Miniopterus orianae oceanensis), occurs across parts of Melbourne ${ }^{25,40}$. Passes identified as M. orianae oceanensis were included in the analyses of bat community composition, however this species is not expected to use bat boxes. All other species are tree-cavity roosting bats and hence potentially could use the bat boxes. Bat passes that were very short, poor quality, or could not be identified to an individual species or a species complex were grouped into 'unknown' bats.

To visualise differences in bat community composition between the different treatments, we performed a non-metric multi-dimensional scaling (NMDS) ordination using the metaMDS function of the 'vegan v2.5-2' package $^{41}$ in R 3.4.1 ${ }^{42}$. The NMDS was performed across two dimensions on the site-by-species matrix using Bray-Curtis dissimilarity, where the species measure was the average number of passes per night per species across the respective survey periods. We produced two NMDS ordinations: the first was based on the Beforeautumn data and was a comparison of the four sites with existing boxes and the 14 without, the second drew on the After-autumn data and was a comparison of the four sites with existing boxes, the four sites that had boxes added, and the 10 control sites. For both of these periods we conducted an ANOVA analysis based on Bray-Curtis dissimilarity using the 'adonis2' function and 999 permutations, to determine whether there were statistically significant differences between the treatment groups in the Before-autumn and After-autumn periods.

As a final step we wanted to determine whether there was an overall effect of the treatments on local bat community diversity. We calculated the Shannon-Wiener $(\mathrm{H})$ diversity at each site, each night in the Before-autumn and After-autumn periods, based on the number of passes identified for each species using the 'diversity' function in the 'vegan' package. We then constructed a linear mixed-effect model (LMM) using the 'lme' function in the 'nlme' package in R, using this nightly diversity as our response variable. We fitted the survey period (Beforeautumn or After-autumn) and site treatment (existing boxes, box addition, and control) as fixed effects, and included an interaction term between the two, specifically to test whether the addition of boxes caused a decrease in diversity in the After-autumn period. We also fitted the site as having a random effect on the intercept, and used a corARMA correlation structure $(p=1, q=1)$ to account for temporal correlation between records taken from successive days.

Long-term bat box checks. The four existing box sites are part of a long-term monitoring program, incorporating 126 bat boxes (Table 1). These boxes comprised nine designs based on those typically used in the Northern Hemisphere ${ }^{11,28}$, attached to trees at heights ranging from $4-6 \mathrm{~m}$ above ground level [see ${ }^{16}$ ]. Boxes were checked during the day for the presence of bats at varying frequencies between 2005 and 2018 (Table 1). During the checks, all bats found roosting in boxes were collected and a range of biometric data were recorded for each individual. As part of an ongoing mark-recapture study, bats were also permanently marked with either a metal-alloy bat-band (Australasian Bird and Bat Banding Scheme) or microchip (Trovan ID100 Passive Implantable Transponder), enabling the total number of individuals to be determined on each check. All bats were either placed back in boxes on the same day (e.g. lactating females and their dependent young during the breeding season), or hand-released near the boxes after sunset.

Ethical approval. All animal capture and handling procedures were carried out under ethics approval from the La Trobe University Animal Ethics Committee (Project Number AEC13-30). All experimental methods were carried out in accordance with relevant guidelines and regulations prescribed by the Department of Environment, Land, Water and Planning (Research Permit Number 10006790).

\section{Results}

Bat detector surveys. We recorded 2938721 bat passes over the combined 18-month Before-entire and the 60-day After-autumn surveys (from 9035 detector nights across all sites combined), of which 1074262 passes $(36.6 \%)$ were identified to 12 species or complexes. The bat community included the eight cavity-roosting species that used the boxes, plus the eastern false pipistrelle (Falsistrellus tasmaniensis), southern free-tailed bat 


\begin{tabular}{|l|l|l|l|l|}
\hline Species & Code & Before-entire & Before-autumn & After-autumn \\
\hline Vespertilionidae & Cg & $288851(30.4 \%)$ & $37044(23.2 \%)$ & $21100(16.9 \%)$ \\
\hline Chalinolobus gouldii & Cm & $132304(13.9 \%)$ & $23385(14.6 \%)$ & $21700(17.4 \%)$ \\
\hline Chalinolobus morio & Ft & $202(0.02 \%)$ & $28(0.02 \%)$ & $97(0.08 \%)$ \\
\hline Falsistrellus tasmaniensis & Nyct & $43752(4.6 \%)$ & $10414(6.5 \%)$ & $6129(4.9 \%)$ \\
\hline Nyctophilus spp. & Scot & $8573(0.9 \%)$ & $1589(1.0 \%)$ & $961(0.8 \%)$ \\
\hline Scotorepens spp. & Vd & $86239(9.1 \%)$ & $17280(10.8 \%)$ & $17095(13.7 \%)$ \\
\hline Vespadelus darlingtoni & Vr & $21540(2.3 \%)$ & $6170(3.9 \%)$ & $3677(2.9 \%)$ \\
\hline Vespadelus regulus & Vv & $207568(21.9 \%)$ & $35468(22.2 \%)$ & $29951(24.0 \%)$ \\
\hline Vespadelus vulturnus & Aa & $15955(1.7 \%)$ & $3967(2.5 \%)$ & $1757(1.4 \%)$ \\
\hline Molossidae & Op & $116837(12.3 \%)$ & $21005(13.2 \%)$ & $18661(15.0 \%)$ \\
\hline Austronomus australis & Or & $1196(0.1 \%)$ & $279(0.2 \%)$ & $416(0.3 \%)$ \\
\hline Ozimops planiceps & \multicolumn{5}{|l|}{} \\
\hline Ozimops ridei & Moo & $26447(2.8 \%)$ & $3012(1.9 \%)$ & $3254(2.6 \%)$ \\
\hline Miniopteridae & \multicolumn{5}{|l}{} \\
\hline Miniopterus orianae oceanensis & 2680780 & 382499 & 257941 \\
\hline Summary & 949464 & 159641 & 124798 \\
\hline Total no. of passes & 1731316 & 222858 & 133143 \\
\hline No. of passes identified & &
\end{tabular}

Table 2. The number of bat passes identified to species or species complexes during three survey periods: Before-entire (4 September 2013 to 23 March 2015); Before-autumn (26 February to 26 April 2014 and 26 February to 23 March 2015); After-autumn (26 February to 26 April 2018). Numbers in parentheses are the percentage of identified passes for each taxa from the total number of identified passes during that survey period. Note that the Before-autumn survey is a subset of the 18-month Before-entire survey dataset.

(Ozimops planiceps), Nyctophilus spp., and the cave-roosting M. orianae oceanensis (Table 2). All 12 species or complexes were recorded at every site (Supplementary Material Fig. S2).

Chalinolobus gouldii comprised the greatest proportion of activity across all 18 sites combined (28.9\% of all identified passes), followed by V. vulturnus (22.1\%), C. morio (14.3\%), O. planiceps (12.6\%), V. darlingtoni (9.6\%) and Nyctophilus spp. (4.6\%; Table 2). The remaining six taxa combined comprised $<8 \%$ of all passes.

There was considerable variation in the species that accounted for the greatest proportion of detections at individual sites. Chalinolobus gouldii and V. vulturnus were the most recorded taxa at seven sites each (C. gouldii: two existing box, two box addition and three control sites; V. vulturnus: two existing boxes and five control sites). Vespadelus darlingtonii comprised the greatest proportion of detections at one box addition site and one control site, as did C. morio (Fig. S2).

Mean $( \pm \mathrm{SD})$ daily maximum and minimum temperatures were similar during the Before-autumn ( $\max$ $23.9 \pm 4.9^{\circ} \mathrm{C}$, $\left.\min 14.1 \pm 2.9^{\circ} \mathrm{C}\right)$ and After-autumn surveys ( $\left.\max 25.0 \pm 4.6, \min 14.0 \pm 2.8^{\circ} \mathrm{C}\right)$, and were comparable to Melbourne's long-term averages over the same dates (26 February to 26 April 1964-2018, max $23.5 \pm 4.5^{\circ} \mathrm{C}$, $\min 13.7 \pm 2.9^{\circ} \mathrm{C}$ ). In contrast, there was some variation in precipitation across the survey periods. During the Before-autumn survey, there was a total of $76.6 \mathrm{~mm}$ of rainfall in 2014 and $49.4 \mathrm{~mm}$ in 2015 , while $43.6 \mathrm{~mm}$ was recorded during the 2018 After-autumn survey. These values were all less than Melbourne's long-term average total rainfall over the same dates (26 February to 26 April 1964-2018, $80.1 \mathrm{~mm})^{43}$.

During the Before-autumn survey, 159641 passes were identified to 12 taxa, with C. gouldii being the most detected species (23.2\% of all passes), followed by V. vulturnus (22.2\%; Table 2). During the After-autumn survey (26 February - 26 April 2018), 124798 passes were identified to the same 12 taxa. Vespadelus vulturnus was detected at a similar proportion between the two periods (24.0\%), while there were proportionally fewer C. gouldii detections during the After-autumn survey (16.9\%; Table 2).

The NMDS ordination indicated that there was little difference in community composition between the site treatments during the Before-autumn and After-autumn surveys (Fig. 1). This was further supported by the subsequent ANOVA, which showed that the bat community did not differ between site treatments during either the Before-autumn (boxes vs no boxes, $\mathrm{F}=0.92$, d.f. $=1, P=0.49$ ) or After-autumn periods (existing boxes vs boxes added vs control, $\mathrm{F}=1.33$, d.f. $=2, P=0.21$ ). There was some evidence of $C$. gouldii comprising a greater proportion of overall bat activity at three of the existing box sites during the Before-autumn survey (Figs. 2, 3a, and Supplementary Material Fig. S2). However, during the After-autumn survey, this species was detected less often and $V$. vulturnus had the highest activity levels at these sites (Figs. 2, 3b and S2). Similarly, at three of the box addition sites, the proportion of C. gouldii was lower during the After-autumn survey than the Before-autumn survey (Figs. 2, 3 and S2). Across the ten control sites there were no consistent patterns in the relative activity of C. gouldii from the Before-autumn to After-autumn detector surveys (Figs. 2, 3 and S2).

Based on the LMM of nightly Shannon-Wiener diversity, there was no evidence that there was a shift in local bat community diversity in response to the addition of the bat boxes (Fig. 4, Supplementary Material Table S2). If anything, the estimated nightly diversity in the After-autumn period was slightly higher at the box addition sites (1.45, cf 1.28 and 1.30 for the existing boxes and control sites, respectively), and there was less of a decline in 

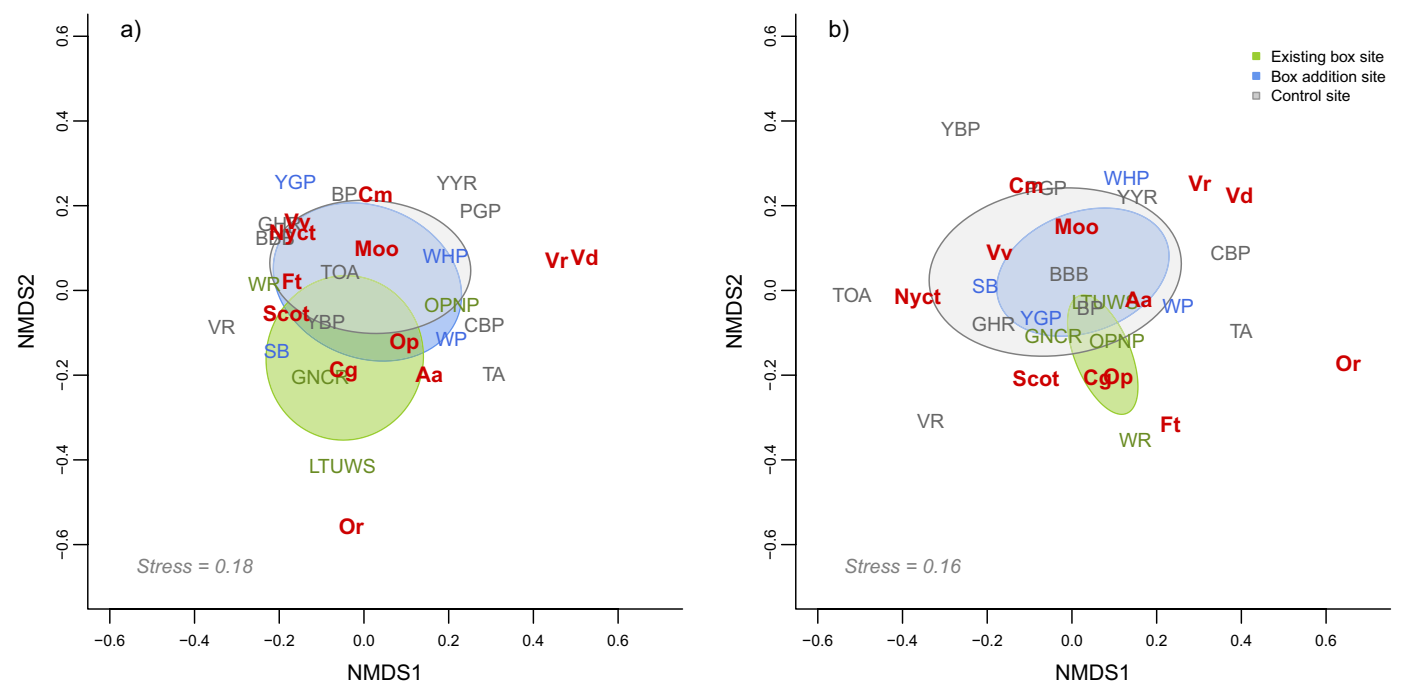

Figure 1. NMDS ordinations of bat community composition, based on the average number of passes of each species per night during two survey periods: (a) Before-autumn, 26 February to 26 April 2014 and 2015; and (b) After-autumn, 26 February to 26 April 2018. Sites are grouped according to treatment; species codes are in red. For full site names and species codes see Tables 1 and 2.

diversity relative to the Before-autumn period (decline of 0.019 at the addition sites $\mathrm{cf} 0.12$ for the existing boxes and 0.087 for the control sites), though there was also substantial error around those estimates (Fig. 4, Table S2).

Long-term bat box checks. A total of 5491 individually banded or microchipped bats, comprising eight species, were recorded using boxes across the four existing box sites between 2005 and 2018. Chalinolobus gouldii was the most common species found using boxes ( 2703 females and 2201 males, $89.3 \%$ of the total numbers), both across all the sites and at each individual site, and was the only species that used the boxes as maternity roosts over multiple years at all sites (Table 3; Supplementary Material Fig. S3).

During the single check of the four box addition sites in December 2017, a total of 508 bats, comprising four species, were recorded using boxes. Vespadelus darlingtoni was the most common species (251 individuals), followed by C. gouldii (237 individuals), S. orion (15 individuals), and C. morio (5 individuals). Most of the V. darlingtoni (236) were from one site (WHP), while C. gouldii comprised the majority of records at the remaining three sites (Fig. 5).

Maternity groups comprising adult females and dependent young of three species (C. gouldii, S. orion and $V$. darlingtoni) were found using the new boxes. Across all four sites, 108 of the 237 C. gouldii were juveniles. Vespadelus darlingtoni bred at two sites, seven of 14 individuals at WP were juveniles, while 115 of the 236 individuals at WHP were juveniles (Fig. S3). Scotorepens orion was only recorded at one site (WP; Fig. 5), where five of the 15 individuals were juveniles.

As considerably more $V$. darlingtoni were recorded during the first check at WHP than have been recorded using boxes previously in Australia, a follow-up check was conducted at this site on 24 May 2018. During this check there were only $14 \mathrm{~V}$. darlingtoni found roosting in the boxes, along with $32 \mathrm{C}$. gouldii and $11 \mathrm{C}$. morio (Fig. 5).

\section{Discussion}

Nest boxes are a common means of providing supplementary microhabitats for cavity-dependent wildlife; however, little is known about their influence on faunal community composition ${ }^{9,44}$. Here, through manual bat box checks and long-term passive acoustic surveys, we compared community composition at four sites where boxes have been used by bats for more than a decade ${ }^{16}$ with sites that either did not have boxes, or sites where boxes were added as part of a BACI experiment. We had predicted that the relative activity of one generalist species $(C$. gouldii) would be greater, and that community diversity would decline, at sites where bat boxes were added compared to sites without boxes. However, despite the fact that C. gouldii continued to dominate use of the existing bat boxes, we found little difference in community composition across the 18 study sites between the 'Before' and 'After' study periods. The relative activity of each species or complex differed between the sites, with no clear or consistent patterns corresponding to the different treatments and survey periods. This suggests that, while use of bat boxes by widespread, adaptable species (such as C. gouldii) may have some influence on localised patterns of community composition ${ }^{26}$, it does not necessarily result in a consistent, widespread dominance of generalist species, or a reduction in overall bat diversity.

During this study, the factors driving patterns in bat community composition were likely to be acting over larger spatial scales than the parks where we conducted bat detector surveys. For example, studies have shown that various forms of disturbance associated with urbanisation, such as artificial night-time lighting ${ }^{45-47}$, housing density ${ }^{40,48,49}$, tree cover ${ }^{50,51}$, the position of major roads ${ }^{52-54}$, and distance to surface water and vegetation structure around waterways $s^{25,55,56}$, form complex interactions that drive spatiotemporal patterns of species 


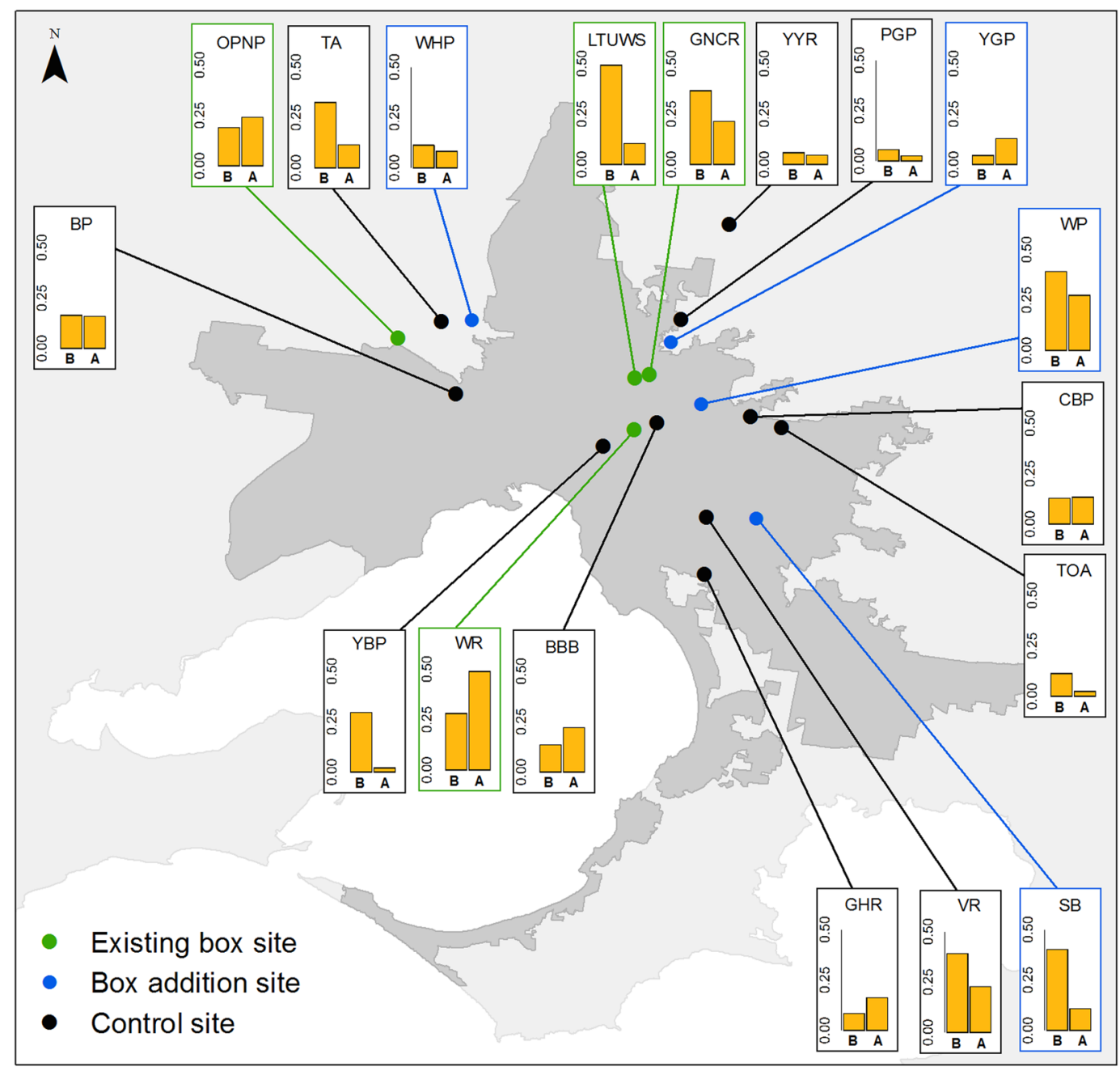

$20 \mathrm{Km}$

Figure 2. Locations of the 18 sites grouped by three treatments (existing boxes, box addition, and control) across Greater Melbourne (dark grey shaded area), Victoria, Australia. Bar charts show proportion of echolocation passes identified as Chalinolobus gouldii at each site during the (B) Before-autumn and (A) Afterautumn surveys. For full site names and species codes see Tables 1 and 2 . This map was constructed in R 3.4.1 ${ }^{42}$ and ArcMap v. $10.7^{67}$, using spatial data that were obtained from open access sources ${ }^{68,69}$.

distribution, abundance and relative activity. Our results suggest that some combination of the above-mentioned factors, along with variation in weather conditions ${ }^{31}$ and abundance of nocturnal arthropods ${ }^{57}$, were stronger drivers of community composition than the presence or absence of bat boxes.

Our long-term mark-recapture data showed that large, discrete populations of C. gouldii used boxes over repeated years at the four existing box sites. These populations included resident adults recaptured over multiple years, juveniles born into the population every year (some of whom subsequently migrated), and immigrants that entered the population. Nonetheless, it remains unclear whether localised increases in numbers of $C$. gouldii occurred at the existing box sites as a direct result of long-term box use ${ }^{26}$, or rather that there was a redistribution of the local populations as individuals incorporated bat boxes into their suite of roost sites, along with natural hollows ${ }^{21}$. While our large bat detector survey effort is likely to have produced accurate measures of the relative activity of different species ${ }^{35,36}$, it is not possible to determine whether the passes were made by members of local colonies roosting at sites with or without boxes, or by individuals that were roosting elsewhere, but were using the site for foraging or commuting.

The question of whether bats that used boxes were members of existing local populations, or individuals that immigrated into a site, is equally relevant to other species that used the newly installed boxes, such as $V$. darlingtoni. The large breeding population of $V$. darlingtoni found at WHP in December 2017 was surprising, especially as it was within 32 months of installing the boxes. As the numbers varied widely between the two box checks at this site, it may be that members of the local population of $V$. darlingtoni incorporated the new bat boxes into the suite of roosts that they use, which would have previously comprised only natural tree cavities or buildings. Box checks and detector surveys would need to be conducted over extended periods (e.g. 5-10 years) to effectively 

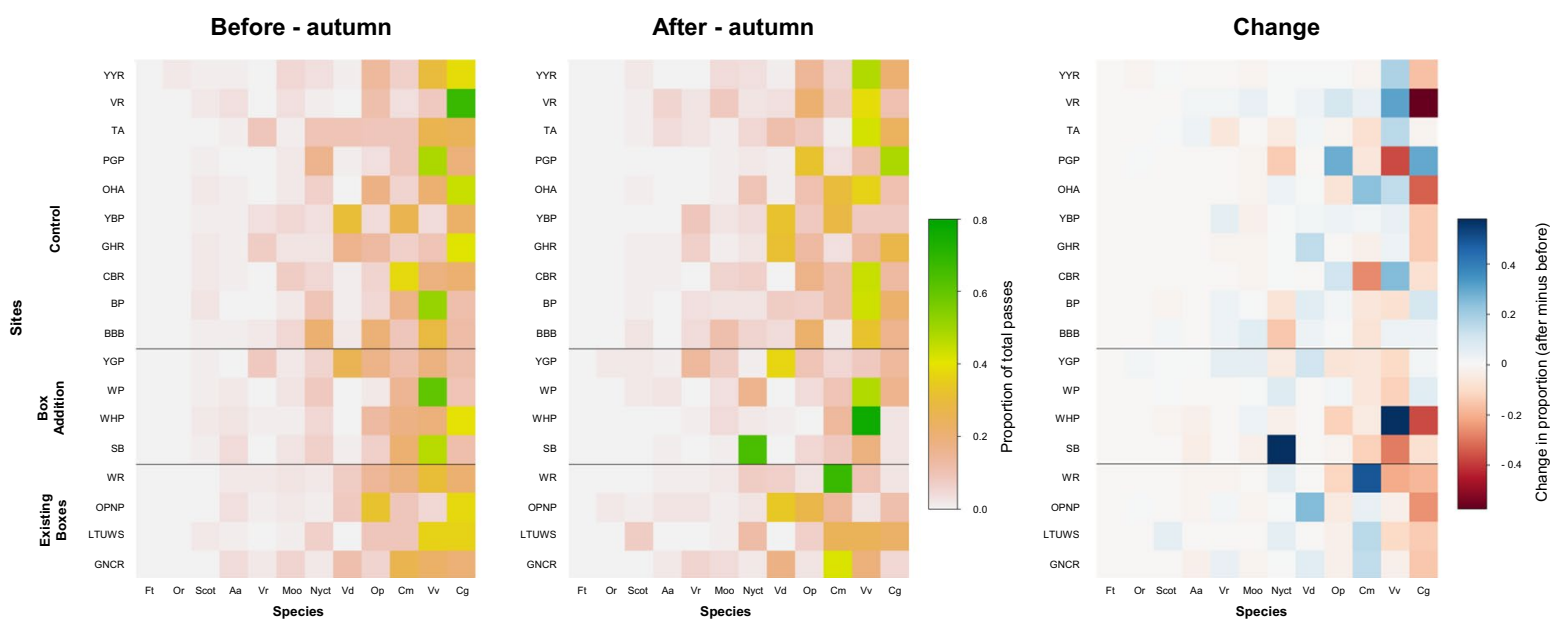

Figure 3. Site by species matrices, shaded according to (a) the proportion of total passes made up by each species in the 'Before-autumn' period, and (b) the proportion of total passes in the 'After-autumn' period. Because these are proportions, rows sum to 1 . In these plots the species are arranged from the least to most dominant, left to right, and the sites are arranged by treatment groups (existing boxes, box addition, control), with different groups being separated by the horizontal black lines. For full site names and species codes see Tables 1 and 2. Plot (c) represents the difference between $(\mathbf{a}, \mathbf{b})$ (i.e. is the 'After-autumn' proportion minus the 'Before-autumn' proportions) - redder colours indicate that the species became less dominant at that site in the 'After-autumn' period, and bluer colours indicate that it became more dominant. If the addition of boxes caused the most common species to become more dominant in the community (and hence make up a greater proportion of passes) then we would expect there to be bluer colours in the far right of the 'Addition' cells in (c), but with the exception of Vespadelus vulturnus ( $\mathrm{Vv}$ ) becoming more dominant at the Woodlands Historic Park (WHP) site, the colours are mostly at the redder end of the spectrum.

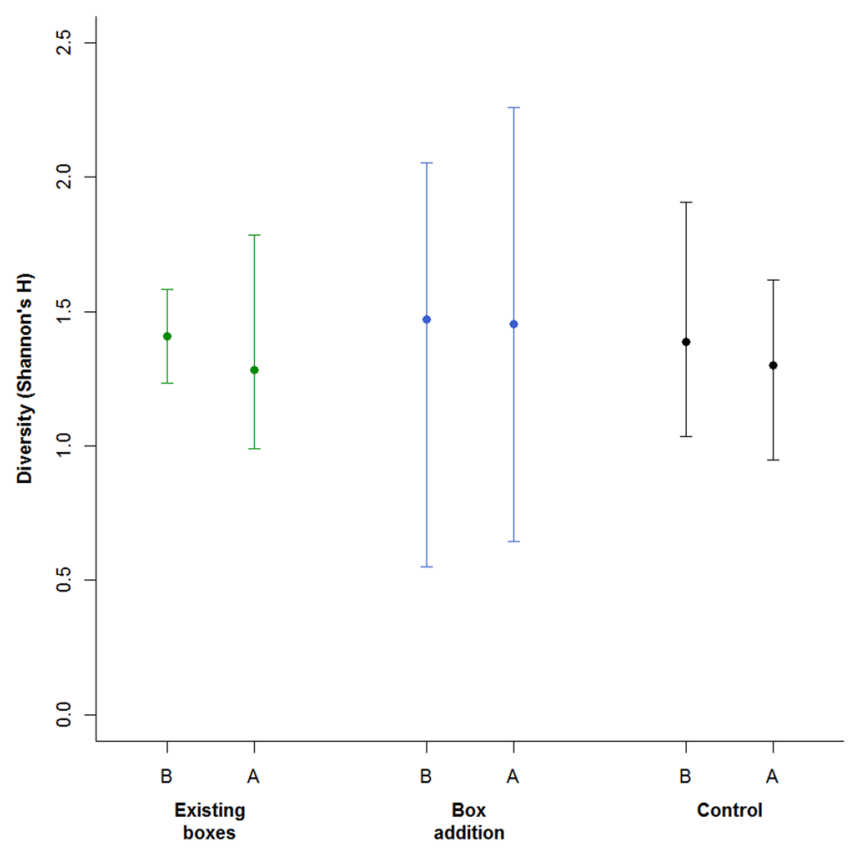

Figure 4. Estimated Shannon-Wiener $(\mathrm{H})$ diversity during the Before-autumn (B) and After-autumn (A) survey periods, based on the number of passes identified for each species per night at each site. Sites are grouped according to treatment (existing boxes, box addition, control). Error bars represent $95 \%$ confidence intervals.

document changes in local population sizes and community structure, as the 32-month time period since box installation may not have been sufficient to reveal significant increases in breeding success leading to larger population numbers. Ultimately, surveys combining trapping, banding and radio-tracking of marked individuals before and after the addition of boxes may be required to determine the source of colonies of bats using boxes. 


\begin{tabular}{|c|c|c|c|c|c|}
\hline \multirow[b]{2}{*}{ Species } & \multicolumn{4}{|c|}{ Site code } & \multirow[b]{2}{*}{ Total (percentage) } \\
\hline & GNCR & LTUWS & OPNP & WR & \\
\hline \multicolumn{6}{|l|}{ Vespertilionidae } \\
\hline Chalinolobus gouldii & 1436 & 1389 & 1530 & 549 & $4904(89.3 \%)$ \\
\hline Chalinolobus morio & 8 & 1 & 6 & 19 & $34(0.6 \%)$ \\
\hline Scotorepens orion & 0 & 1 & 0 & 39 & $40(0.7 \%)$ \\
\hline Vespadelus darlingtoni & 9 & 3 & 128 & 18 & $158(2.8 \%)$ \\
\hline Vespadelus regulus & 0 & 0 & 1 & 0 & $1(0.02 \%)$ \\
\hline Vespadelus vulturnus & 0 & 0 & 9 & 0 & $9(0.2 \%)$ \\
\hline \multicolumn{6}{|l|}{ Molossidae } \\
\hline Austronomus australis & 149 & 49 & 141 & 5 & $344(6.3 \%)$ \\
\hline Ozimops ridei & 0 & 0 & 1 & 0 & $1(0.02 \%)$ \\
\hline Total & 1602 & 1443 & 1816 & 630 & 5491 \\
\hline
\end{tabular}

Table 3. The number of banded or microchipped bats that used boxes at the four existing box sites from 20052018. For full site names and site-specific survey effort see Table 1. Numbers in parentheses are the percentage of each species of the total number of marked bats across the four sites.z.

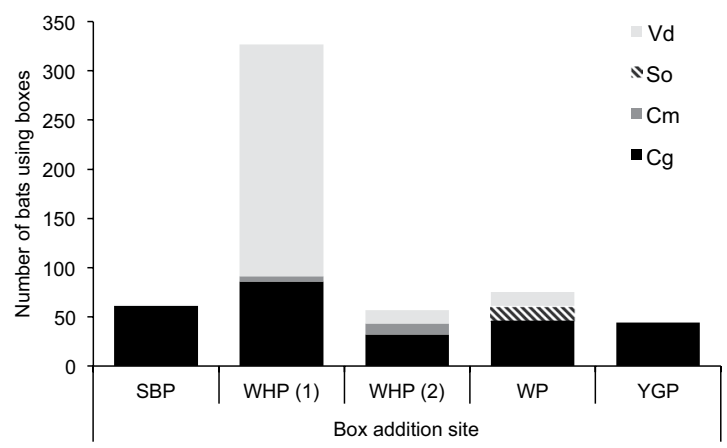

Figure 5. Summary of bats using boxes during checks conducted in December 2017 at the four box addition sites. For full site names and species codes see Tables 1 and 2. Data from the two checks at WHP are shown separately: (1) 13 December 2017, and (2) 24 May 2018. Note - the Scotorepens spp. found using boxes was $S$. orion.

The vast number of nest boxes placed in the environment worldwide represents habitat supplementation on a similar scale to other well-intentioned human activities, such as bird feeding ${ }^{58}$. Interestingly, large-scale bird feeding has been shown to strongly influence the structuring of bird communities in urbanised areas ${ }^{59}$. It is therefore surprising that only limited research has addressed similar questions relating to the potential flow-on effects of nest box programs $s^{60}$. To our knowledge, our study is the first to explore the link between the provision of artificial cavities and changes in bat community composition over spatial and temporal scales relevant to management, and over time frames in which boxes become occupied. While we did not find strong evidence that bat box use influenced localised community structure, this is an area that warrants investigation for bat box programs conducted in other systems, and more broadly for nest box programs targeting other groups of cavity-dependent wildlife. Studies employing BACI surveys designed to monitor changes in localised community composition and species' abundance in situations where nest boxes are used to compensate for the removal of mature, cavity-bearing trees ${ }^{3}$ would be particularly informative.

Our long-term bat box program has been successful in attracting several bat species, some of which use the boxes throughout the year, including as maternity roosts. The mark-recapture data generated has helped us gain insights into various aspects of the ecology of the bats that use the boxes ${ }^{61,62}$. While the program has not achieved the a priori objective of providing supplementary roosting habitats for all species of bats (i.e. at the community level), it does not appear to have had an overall detrimental effect on localised bat communities across Greater Melbourne, as we had predicted ${ }^{16,26}$. Our findings suggest that, despite large resident populations of one highly adaptable, generalist species consistently using boxes, that the parks and reserves that we sampled, and the surrounding areas across Melbourne's highly modified urban landscape, have adequate foraging and roosting resources to maintain a relatively diverse community of cavity-roosting bats.

Given that many disturbance-sensitive species have not used bat boxes to date ${ }^{9}$, there is great need for developing and testing novel techniques of providing supplementary roosts for cavity-dependent bats in human-disturbed environments; ${ }^{16,63,64}$ for example, using chainsaws to mechanically excavate cavities into the trunk or branches of trees ${ }^{65}$. However, where possible, the retention of mature, hollow-bearing trees should be the primary objective of conservation and management programs targeting cavity-dependent wildlife in disturbed landscapes ${ }^{2}$, such as parks and reserves located within an urban matrix ${ }^{66}$. 


\section{Data availability}

The datasets generated during and/or analysed during the current study are available from the corresponding author on request.

Received: 14 February 2020; Accepted: 20 March 2020; Published online: 10 April 2020

\section{References}

1. Remm, J. \& Lõhmus, A. Tree cavities in forests - the broad distribution pattern of a keystone structure for biodiversity. For. Ecol. Manage. 262, 579-585 (2011).

2. Manning, A. D., Gibbons, P., Fischer, J., Oliver, D. L. \& Lindenmayer, D. B. Hollow futures? Tree decline, lag effects and hollowdependent species. Anim. Conserv. 16,395-403 (2013).

3. Lindenmayer, D. B. et al. The anatomy of a failed offset. Biol. Conserv. 210, 286-292 (2017).

4. Berthier, K., Leippert, F., Fumagalli, L. \& Arlettaz, R. Massive nest-box supplementation boosts fecundity, survival and even immigration without altering mating and reproductive behaviour in a rapidly recovered bird population. PLoS One 7, e36028 (2012).

5. Brazill-Boast, J., Pryke, S. R. \& Griffith, S. C. S. C. Provisioning habitat with custom-designed nest-boxes increases reproductive success in an endangered finch. Austral Ecol. 38, 405-412 (2013).

6. Harley, D. An overview of actions to conserve Leadbeater's Possum (Gymnobelideus leadbeateri). Vic. Nat. 133, 85-97 (2016).

7. Charter, M., Izhaki, I., Ben Mocha, Y. \& Kark, S. Nest-site competition between invasive and native cavity nesting birds and its implication for conservation. J. Environ. Manage. 181, 129-134 (2016).

8. Olah, G., Vigo, G., Heinsohn, R. \& Brightsmith, D. J. Nest site selection and efficacy of artificial nests for breeding success of Scarlet Macaws Ara macao macao in lowland Peru. J. Nat. Conserv. 22, 176-185 (2014).

9. Mering, E. D. \& Chambers, C. L. Thinking outside the box: a review of artificial roosts for bats. Wildl. Soc. Bull. 38, 741-751 (2014).

10. Stebbings, R. E. \& Walsh, S. T. Bat Boxes: A Guide to the History, Function, Construction and use in the Conservation of Bats. (Bat Conservation Trust, 1991).

11. Tuttle, M. D., Kiser, M. \& Kiser, S. The Bat House Builder's Hand-book. (Bat Conservation International, 2013).

12. Mering, E. D. \& Chambers, C. L. Artificial roosts for tree-roosting bats in northern Arizona. Wildl. Soc. Bull. 36, 765-772 (2012).

13. Kerth, G., Weissmann, K. \& Konig, B. Day roost selection in female Bechstein's bats (Myotis bechsteinii): a field experiment to determine the influence of roost temperature. Oecologia 126, 1-9 (2001).

14. Agnelli, P., Maltagliati, G., Ducci, L. \& Cannicci, S. Artificial roosts for bats: education and research. The 'be a bat's friend' project of The Natural History Museum of The University of Florence. Hystrix-Italian. J. Mammal. 22, 215-223 (2011).

15. López-Baucells, A. et al. Bat boxes in urban non-native forests: a popular practice that should be reconsidered. Urban Ecosyst. 20, 217-225 (2017).

16. Griffiths, S. R. et al. Bat boxes are not a silver bullet conservation tool. Mamm. Rev. 47, 261-265 (2017).

17. van der Ree, R. \& McCarthy, M. A. Inferring persistence of indigenous mammals in response to urbanisation. Anim. Conserv. 8, 309-319 (2005)

18. Jung, K. \& Kalko, E. K. V. Where forest meets urbanization: foraging plasticity of aerial insectivorous bats in an anthropogenically altered environment. J. Mammal. 91, 144-153 (2010).

19. Russo, D. \& Ancillotto, L. Sensitivity of bats to urbanization: a review. Mamm. Biol. 80, 205-212 (2015).

20. Jung, K. \& Threlfall, C. G. Urbanisation and Its Effects on Bats-A Global Meta-Analysis. in Bats in the Anthropocene: Conservation of Bats in a Changing World (eds. Voigt, C. C. \& Kingston, T.) 13-33 (Springer International Publishing, 2016).

21. Evans, L. N. \& Lumsden, L. F. A comparison of the roosting behaviour of Gould's wattled bats Chalinolobus gouldii using bat boxes and tree hollows in suburban Melbourne. in Biology and Conservation of Australasian Bats (eds. Law, B., Eby, P., Lunney, D. \& Lumsden, L.) 288-296 (Royal Zoological Society of New South Wales, 2011).

22. Rhodes, M. \& Jones, D. The use of bat boxes by insectivorous bats and other fauna in the greater Brisbane region. in Biology and Conservation of Australasian Bats (eds. Law, B., Eby, P., Lunney, D. \& Lumsden, L.) 424-442 (Royal Zoological Society of New South Wales, 2011).

23. Irvine, R. \& Bender, R. Initial results from bat roosting boxes at Organ Pipes National Park. Vic. Nat. 112, 212-218 (1995).

24. Evans, L. N. Roosting behaviour of urban microbats: the influence of ectoparasites, roost microclimate and sociality. Faculty of Veterinary Science (PhD Thesis. The University of Melbourne, Melbourne, Victoria, 2009).

25. Straka, T. M., Lentini, P. E., Lumsden, L. F., Wintle, B. A. \& van der Ree, R. Urban bat communities are affected by wetland size, quality, and pollution levels. Ecol. Evol. 6, 4761-4774 (2016).

26. Griffiths, S. R. et al. Long-term monitoring suggests bat boxes alter local bat community structure. Aust. Mammal. 41, 273-278 (2018).

27. Larson, D. J. \& Hayes, J. P. Variability in sensitivity of Anabat II bat detectors and a method of calibration. Acta Chiropterologica 2, 209-213 (2000)

28. Stebbings, R. E. \& Walsh, S. T. Bat Boxes. (Fauna \& Flora Preservation Society, 1985).

29. Hines, J. The 'Tanglewood Wedge' bat-box. Batchat 1, 5-6 (1985).

30. Gonsalves, L. \& Law, B. S. Seasonal activity patterns of bats in North Sydney, New South Wales: implications for urban bat monitoring programs. Aust. Mammal. 40, 220-229 (2017).

31. Milne, D. J., Fisher, A., Rainey, I. \& Pavey, C. R. Temporal patterns of bats in the Top End of the Northern Territory, Australia. J. Mammal. 86, 909-920 (2005).

32. Hayes, J. P. Temporal variation in activity of bats and the design of echolocation-monitoring studies. J. Mammal. 78, 514-524 (1997).

33. Kuenzi, A. J. \& Morrison, M. L. Temporal patterns of bat activity in southern Arizona. J. Wildl. Manage. 67, 52-64 (2003).

34. Fenton, M. B., Boyle, N. G. H., Harrison, T. M. \& Oxley, D. J. Activity patterns, habitat use, and prey selection by some African insectivorous bats. Biotropica 9, 73-85 (1977).

35. Law, B. S., Gonsalves, L., Tap, P., Penman, T. \& Chidel, M. Optimizing ultrasonic sampling effort for monitoring forest bats. Austral Ecol. 40, 886-897 (2015).

36. Fischer, J., Stott, J., Law, B. S., Adams, M. D. \& Forrester, R. I. Designing effective habitat studies: quantifying multiple sources of variability in bat activity. Acta Chiropterologica 11, 127-137 (2009).

37. Lumsden, L. F. \& Bennett, A. F. Scattered trees in rural landscapes: foraging habitat for insectivorous bats in south-eastern Australia. Biol. Conserv. 122, 205-222 (2005).

38. Adams, M. D., Law, B. S. \& Gibson, M. S. Reliable automation of bat call identification for eastern New South Wales, Australia, using classification trees and AnaScheme software. Acta Chiropterologica 12, 231-245 (2010).

39. Gibson, M. S. \& Lumsden, L. F. The AnaScheme automated bat call identification system. Australas. Bat Soc. Newsl. 20, 24-27 (2003).

40. Caryl, F. M., Lumsden, L. F., van der Ree, R. \& Wintle, B. A. Functional responses of insectivorous bats to increasing housing density support 'land-sparing' rather than 'land-sharing' urban growth strategies. J. Appl. Ecol. 53, 191-201 (2016).

41. Oksanen, J. et al. vegan: Community Ecology Package. R Package version 2.5-2'. (2018). 
42. R Development Core Team. R: A Language and Environment for Statistical Computing. R Foundation for Statistical Computing, Vienna vol. 1 (2011).

43. Australian Bureau of Meteorology. Climate Data Online, http://www.bom.gov.au/climate/data/ (2018).

44. Valera, F., Václav, R., Calero-Torralbo, Á. M., Martínez, T. \& Veiga, J. Natural cavity restoration as an alternative to nest box supplementation. Restor. Ecol. 27, 220-227 (2018).

45. Stone, E. L., Jones, G. \& Harris, S. Street lighting disturbs commuting bats. Curr. Biol. 19, 1123-1127 (2009).

46. Stone, E. L., Harris, S. \& Jones, G. Impacts of artificial lighting on bats: a review of challenges and solutions. Mamm. Biol. 80, 213-219 (2015).

47. Rodríguez-Aguilar, G., Orozco-Lugo, C. L., Vleut, I. \& Vazquez, L. B. Influence of urbanization on the occurrence and activity of aerial insectivorous bats. Urban Ecosyst. 20, 477-488 (2017).

48. Threlfall, C. G., Law, B. S. \& Banks, P. B. Sensitivity of insectivorous bats to urbanization: implications for suburban conservation planning. Biol. Conserv. 146, 41-52 (2012).

49. Gaisler, J., Zukal, J., Rehak, Z. \& Homolka, M. Habitat preference and flight activity of bats in a city. J. Zool. 244, 439-445 (1998).

50. Treby, D. L. \& Castley, J. G. Determinants of microbat communities in urban forest remnants: a rapid landscape scale assessment. Urban Ecosyst. 19, 1351-1371 (2016).

51. Gehrt, S. D. \& Chelsvig, J. E. Bat activity in an urban landscape: patterns at the landscape and microhabitat scale. Ecol. Appl. 13, 939-950 (2003).

52. Lesinski, G., Sikora, A. \& Olszewski, A. Bat casualties on a road crossing a mosaic landscape. Eur. J. Wildl. Res. 57, 217-223 (2011).

53. Berthinussen, A. \& Altringham, J. The effect of a major road on bat activity and diversity. J. Appl. Ecol. 49, 82-89 (2012).

54. Kerth, G. \& Melber, M. Species-specific barrier effects of a motorway on the habitat use of two threatened forest-living bat species. Biol. Conserv. 142, 270-279 (2009).

55. Lintott, P. R., Bunnefeld, N. \& Park, K. J. Opportunities for improving the foraging potential of urban waterways for bats. Biol. Conserv. 191, 224-233 (2015).

56. Ancillotto, L., Bosso, L., Salinas-Ramos, V. B. \& Russo, D. The importance of ponds for the conservation of bats in urban landscapes. Landsc. Urban Plan. 190, 103607 (2019).

57. Threlfall, C. G., Law, B. S. \& Banks, P. B. Influence of landscape structure and human modifications on insect biomass and bat foraging activity in an urban landscape. PLoS One 7, 10 (2012).

58. Galbraith, J. A., Jones, D. N., Beggs, J. R., Parry, K. \& Stanley, M. C. Urban bird feeders dominated by a few species and individuals. Front. Ecol. Evol. 5, 81 (2017).

59. Galbraith, J. A., Beggs, J. R., Jones, D. N. \& Stanley, M. C. Supplementary feeding restructures urban bird communities. Proc. Natl. Acad. Sci. 112, E2648-E2657 (2015).

60. von Post, M. \& Smith, H. G. Effects on rural House Sparrow and Tree Sparrow populations by experimental nest-site addition. J. Ornithol. 156, 231-237 (2015).

61. Lentini, P. E., Bird, T. J., Griffiths, S. R., Godinho, L. N. \& Wintle, B. A. A global synthesis of survival estimates for microbats. Biol. Lett. 11, 20150371 (2015).

62. Godinho, L. N., Lumsden, L. F., Coulson, G. \& Griffiths, S. R. Network analysis reveals cryptic seasonal patterns of association in Gould's wattled bats (Chalinolobus gouldii) roosting in bat-boxes. Behaviour 152, 2079-2105 (2015).

63. Martin Bideguren, G. et al. Bat boxes and climate change: testing the risk of over-heating in the Mediterranean region. Biodivers. Conserv. 28, 21-35 (2018).

64. Rueegger, N., Goldingay, R. L., Law, B. S. \& Gonsalves, L. Limited use of bat boxes in a rural landscape: Implications for offsetting the clearing of hollow-bearing trees. Restor. Ecol. 27, 901-911 (2018).

65. Griffiths, S. R. et al. Chainsaw-carved cavities better mimic the thermal properties of natural tree hollows than nest boxes and log hollows. Forests 9, 235 (2018).

66. Stagoll, K., Lindenmayer, D. B., Knight, E., Fischer, J. \& Manning, A. D. Large trees are keystone structures in urban parks. Conserv. Lett. 5, 115-122 (2012).

67. ESRI. AM v. 10.7. ESRI, Redlands, CA, USA (2019).

68. The State of Victoria, Department of Environment, Land, W. and Planning. Planning scheme Urban Growth Boundary - Vicmap Planning, http://www.data.vic.gov.au/data/dataset/planning-scheme-urban-growth-boundary-vicmap-planning (2017).

69. Geosciences Australia. Geodata Coast 100K 2004, http://www.ga.gov.au/metadata-gateway/metadata/record/gcat_61395 (2004).

\section{Acknowledgements}

We thank Robert Bender, Lisa Godinho, Robert Irvine, Danielle Eastick, Casey Visintin, Emmi van Harten, Catherine Payne, Melissa Walker, Alicia Dimovski and Kristin Semmens for their assistance during fieldwork, plus the many volunteers who have generously contributed their time during bat box checks. Phoebe Macak and Andrew Bennett provided useful comments on an earlier draft of the manuscript. This study was funded by the Parks Victoria Research Partners Panel (grant to SRG and KAR), the Holsworth Wildlife Research Endowment (grant to SRG), the Wettenhall Environment Trust (grant to SRG and the Friends of Organ Pipes National Park), the M.A. Ingram Trust (grant to SRG), and with support from the Victorian Government. SRG was supported by an Australian Government Research Training Program Scholarship. PEL is supported by ARC Linkage Project LP160100439.

\section{Author contributions}

Conceptualization: S.R.G. and L.F.L.; Methodology: S.R.G. and L.F.L.; Data curation: S.R.G. and P.E.L.; Formal analysis: P.E.L. and S.R.G.; Investigation: S.R.G.; Writing- Original draft preparation: S.R.G.; Writing- Reviewing and editing: S.R.G., P.E.L., L.F.L. and K.A.R.; Visualization: P.E.L. and S.R.G.; Project administration: S.R.G. and K.A.R.; Funding acquisition: S.R.G. and K.A.R.

\section{Competing interests}

The authors declare no competing interests.

\section{Additional information}

Supplementary information is available for this paper at https://doi.org/10.1038/s41598-020-63003-w.

Correspondence and requests for materials should be addressed to S.R.G.

Reprints and permissions information is available at www.nature.com/reprints. 
Publisher's note Springer Nature remains neutral with regard to jurisdictional claims in published maps and institutional affiliations.

(c) (i) Open Access This article is licensed under a Creative Commons Attribution 4.0 International License, which permits use, sharing, adaptation, distribution and reproduction in any medium or format, as long as you give appropriate credit to the original author(s) and the source, provide a link to the Creative Commons license, and indicate if changes were made. The images or other third party material in this article are included in the article's Creative Commons license, unless indicated otherwise in a credit line to the material. If material is not included in the article's Creative Commons license and your intended use is not permitted by statutory regulation or exceeds the permitted use, you will need to obtain permission directly from the copyright holder. To view a copy of this license, visit http://creativecommons.org/licenses/by/4.0/.

(c) The Author(s) 2020 